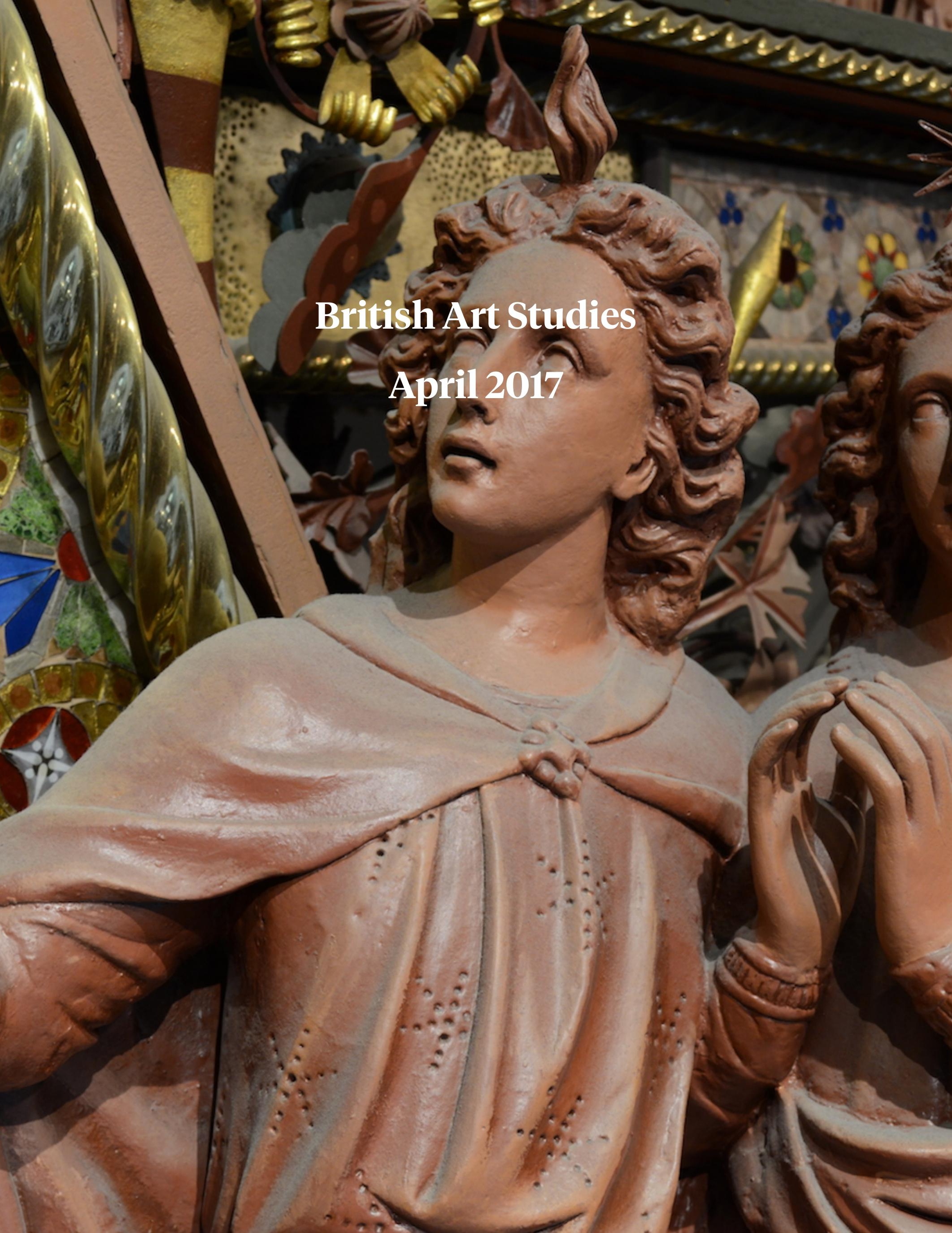


British Art Studies

Issue 5, published 17 April 2017

Cover image: Francis Alexander Skidmore and Sir George Gilbert Scott, Hereford Screen (detail), 1862, painted wrought and cast iron, brass, copper, timber, mosaics, and hardstones. Collection of the Victoria \& Albert Museum, London, Given by Herbert Art Gallery and Museum, Coventry (M.251:1 to 316-1984).. Digital image courtesy of Justin Underhill

PDF generated on 14 April 2022

Note: British Art Studies is a digital publication and intended to be experienced online and referenced digitally. PDFs are provided for ease of reading offline. Please do not reference the PDF in academic citations: we recommend the use of DOIs (digital object identifiers) provided within the online article. These unique alphanumeric strings identify content and provide a persistent link to a location on the internet. A DOI is guaranteed never to change, so you can use it to link permanently to electronic documents with confidence.

Published by:

Paul Mellon Centre 16 Bedford Square London, WC1B 3JA https://www.paul-mellon-centre.ac.uk

In partnership with:

Yale Center for British Art 1080 Chapel Street New Haven, Connecticut https://britishart.yale.edu

ISSN: 2058-5462

DOI: $10.17658 /$ issn.2058-5462

URL: https://www.britishartstudies.ac.uk

Editorial team: https://www.britishartstudies.ac.uk/about/editorial-team Advisory board: https://www.britishartstudies.ac.uk/about/advisory-board

Produced in the United Kingdom. 


\section{Contents}

Sound and Vision in the Hereford Screen, Justin Underhill 


\title{
Sound and vision in the Hereford Screen
}

\author{
Justin Underhill
}

\section{Abstract}

This article describes some recent digital documentation of Hereford Cathedral and the Hereford Screen, which I have developed as part of this "One Object" feature. Virtual reconstruction allows for the identification of significant standpoints within the cathedral that would have dramatically impacted on the appearance of the screen. The role of sound in structuring viewer experience at these standpoints is also explored. The reconstructions demonstrate that the Hereford Screen anticipated (and structured) the movement of the beholder in the cathedral, and that its sculptural programme served to visualize the very process of devotion for those who approached it.

\section{Authors}

Mellon Postdoctoral Fellow in the Digital Humanities at University of California, Berkeley

\section{Acknowledgements}

This study would not have been possible without the assistance and support of Ayla Lepine, Alicia Robinson, Tom Scutt, Baillie Card, and Sarah Victoria Turner. This article is dedicated to Claudia von Vacano.

\section{Cite as}

Justin Underhill, "Sound and Vision in the Hereford Screen", British Art Studies, Issue 5, https://dx.doi.org/10.17658/issn.2058-5462/issue-05/ junderhill 


\section{Objects and Embodied Experience}

The role of museums in structuring our perceptions of works of art is easy to take for granted. Gallery spaces are, after all, designed to maximize visual access to the objects displayed within them, with mute, low-contrast walls and high levels of ambient light that foreground visual details. However, these conditions can obscure how objects under observation tended to be experienced in their original contexts, designed as they were for diverse environments often strikingly different from the modern museum. Fortunately, contemporary technology allows us to reconstruct some of these occluded parameters.

In this essay, I use laser scanning and photogrammetry to demonstrate how the Hereford Screen was experientially anchored within the interior space of Hereford Cathedral. Additionally, I demonstrate how the significant visual qualities of the screen emerged within the soundscape of the cathedral. Since these effects fail to register in the standard documentary practices of art history, such as photography, the visualizations produced here are also an attempt to innovatively map out multimodal dimensions of embodied experience as they bear upon (and are in turn constructed by) a single artefact.

\section{Digital Documentation of the Screen and Cathedral}

Although available plans and elevations provided sufficient data to model most of the flat surfaces in the cathedral, additional information was needed to model the complex vaulting seen throughout the building. When plans and elevations do not provide sufficient data to model all of the surfaces that comprise an architectural complex, laser scanning provides a means of digitally documenting a site in exhaustive detail. Laser scanners bounce pencils of focused light off nearby objects, and extract geometric data about these surfaces when light is reflected back. What we are seeing in Figure 1 are the results of such scanning processed into a point cloud, a threedimensional array of points in coordinate space that describe the surface geometry of one or more objects. It is colour scaled to highlight architectural components (nave in blue, Lady Chapel in yellow, tower missing from scan). Point clouds can be further processed to produce photorealistic threedimensional models with continuous surfaces, such as those commonly seen in film, gaming, and related new media. 


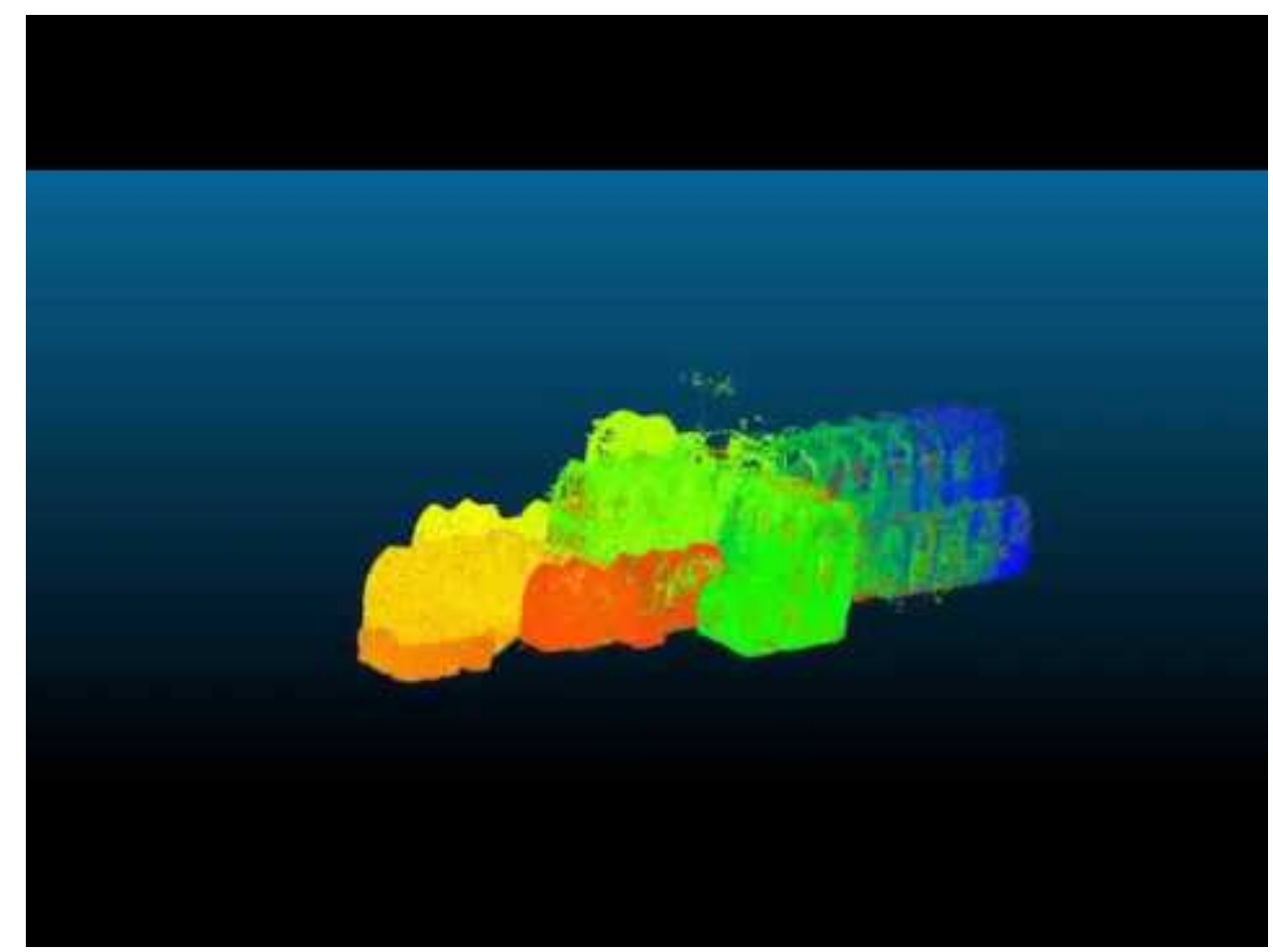

Watch Video

\section{Figure 1.}

Point Cloud of Hereford Cathedral, colour scaled to highlight architectural components (nave in blue, Lady Chapel in yellow). (Tower missing from scan; modelled from plans and elevations). Digital image courtesy of Rendering produced by Justin Underhill.

In order to construct a replete digital model of Hereford Cathedral, it was laser scanned in October 2016 using the ZEB1 handheld scanner produced by GEOSLAM technologies. These results, shown in Figure 1, were processed in PointCab software, capable of producing plans and elevations of any section of the point cloud that was selected (figs. $\underline{2}$ and $\underline{3}$ ). These plans were used to construct a simplified model of the cathedral for processing in Odeon Room Acoustics Software. 


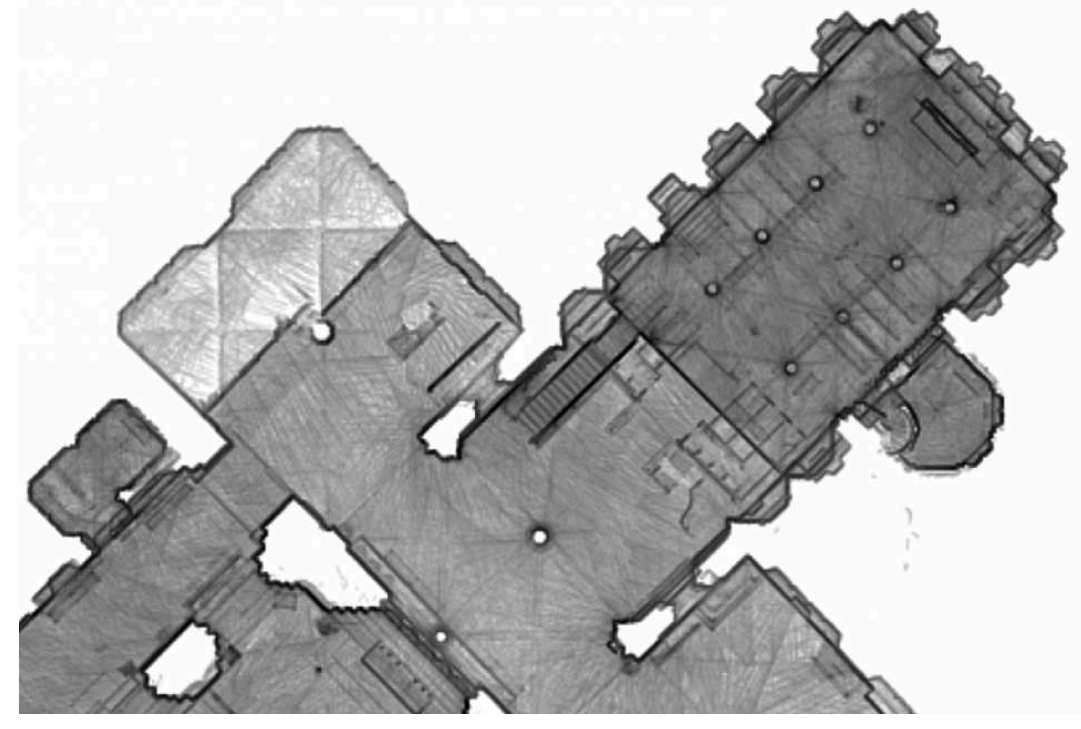

Figure 2.

Plan of the Lady Chapel of Hereford Cathedral, generated by PointCab. Digital image courtesy of Justin Underhill

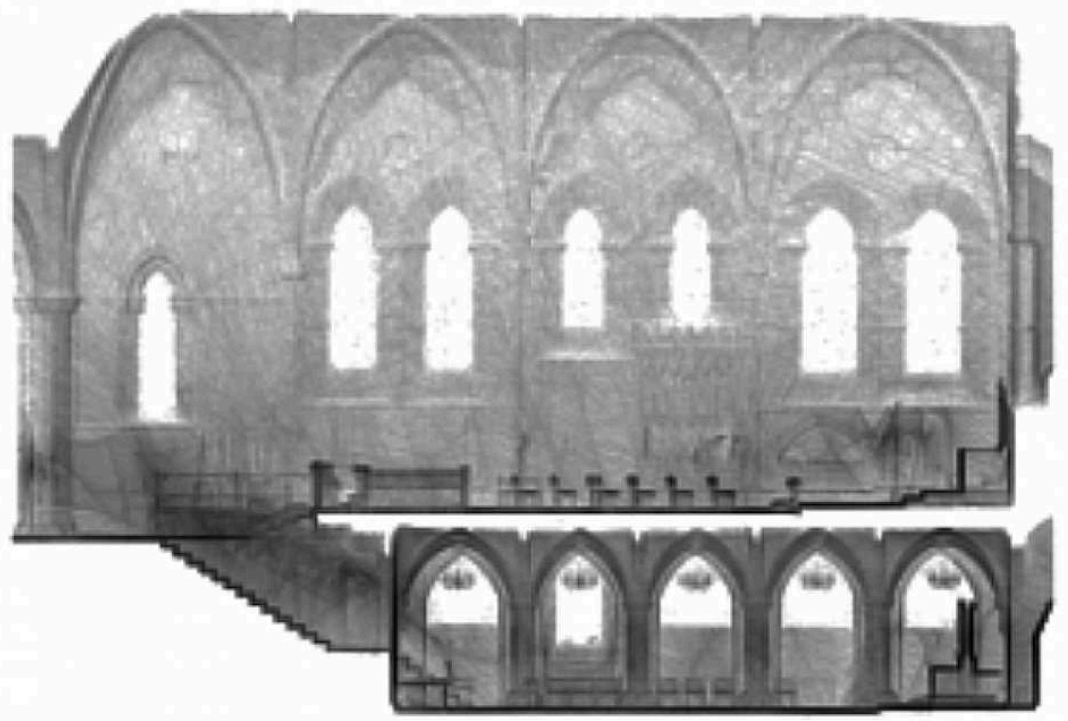

Figure 3.

Elevation (with crypt) of the Lady Chapel of Hereford Cathedral, generated by PointCab. Digital image courtesy of Justin Underhill 


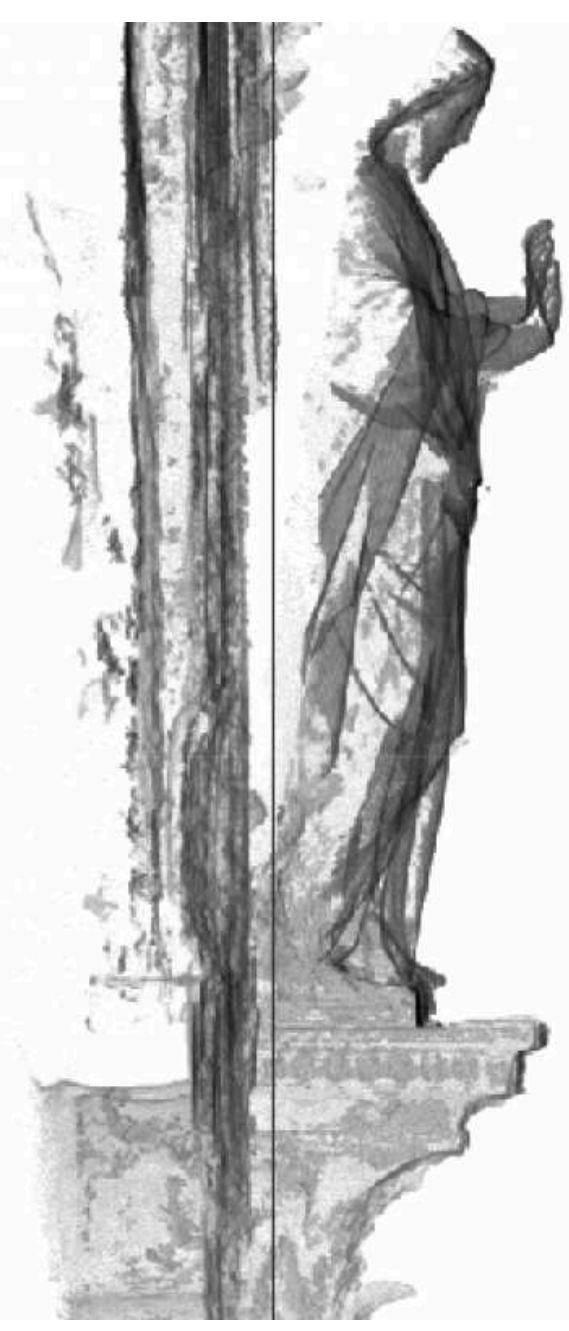

Figure 4.

Section of photogrammetric capture of Christ, Hereford Screen, generated by PointCab. Digital image courtesy of Justin Underhill

This same process was used to record features of the Hereford Screen. Although detailed plans and elevations provided enough data to sufficiently model the major components of the screen, such as the columns, mandorla, and tracery, very little information about the sculptures on top of the screen was available. To supplement these results, digital photogrammetry was also used. When high-quality digital photos of an object are processed by photogrammetric software, recurring pixels are matched and surfaces are interpolated, providing a three-dimensional reconstruction of the object. Digital photogrammetry is particularly useful for documenting surfaces that are out of a scanner's range, or otherwise inaccessible. In early November, four hundred 36.3 megapixel photos of the Hereford Screen were taken using a tethered Nikon D800 mounted on a MegaMast 8.4-metre tripod. These photos were processed in RealityCapture software to produce high-quality meshes. A cross section of one of these meshes, a digital capture of the central figure of Christ, is shown in figure 4 . The digital models produced by 
the processes described above allow us to develop a phenomenological understanding of the liturgical space that they defined. By simulating the perceptual affordances of the screen as it was installed in the cathedral building, we can better understand its formal structure, specifically in relation to the embodied practices of looking, moving, and listening as they were grounded in devotional practice.

\section{Approaching the Screen}

Present-day visitors to the $V \& A$ must approach the screen from either side of the gallery (though the top portion of the screen is visible from the museum's main entrance) and the viewer's movement is presently constrained such that the screen can only be viewed from a maximal distance of 3.3 metres (unless they retreat to the stairwells that lead from the lobby of the museum to the second floor). The far more expansive cathedral interior, with a maximal viewing distance of about 48 metres, would have afforded a different viewing experience: one in which the optical detail of the screen emerged as viewers traversed the nave. Most importantly, motion parallax-the transformation of an object's apparent size and orientation as a function of the observer's motion-would have dramatically structured the viewer's experience of the screen.

The screen's central sculptural grouping is multiplanar: a rear plane consists of the crucifix and the decorative grillwork; the middle plane is occupied by Christ (the focal point of the entire ensemble); and on either side of the frontal plane, the attendant angels have been placed on pilasters. As seen in figure 5 , these planes notionally compress in distant viewing; from the rear portion of the nave, the angels would seem to look directly at Christ, with the exception of the leftmost one, who looks upwards analeptically towards the crucifix mounted atop the screen. However, as viewers approached the screen, moving from point $A$ to point $B$ in figure 5 , the distance between the sculptural figures would have become apparent, and the angle that subtends the gaze of each angel would have seemed to grow larger. The penetrating stare that three of the angels once directed at Christ would slowly seem to "swing up", now directed towards the cross on the central axis of the rear plane. Moreover, from a viewing distance of about 8.36 metres-a space originally defined according to where the nave of the cathedral meets the crossing-Christ stares directly at the viewer. With Christ watching, a viewer would have their own visual experience of the sculptural group as they approached the crossing; the angels, looking up, turn their attention to the same symbol of the crucifixion that stood on the holy table, framed by the screen at the east of the choir. 


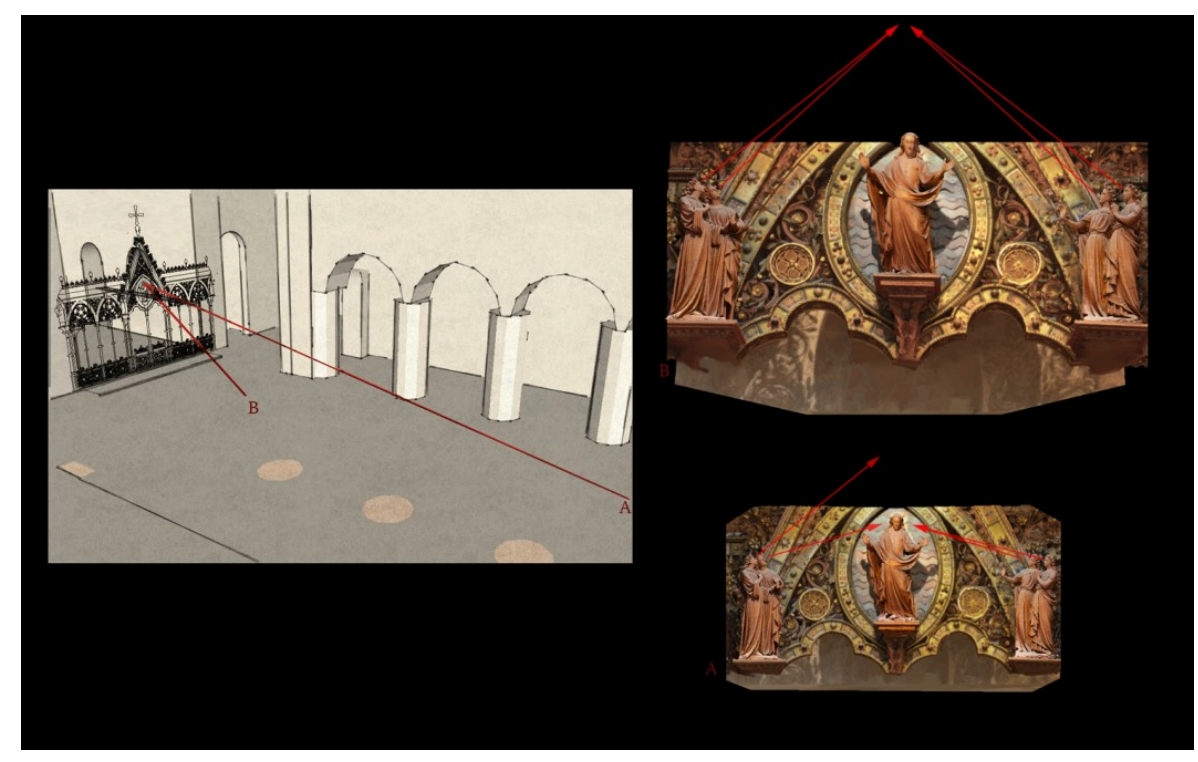

Figure 5.

Standpoint and the visual address of the sculptural figures of the Hereford Screen, Digital image courtesy of Justin Underhill

\section{The Hereford Screen and its Soundscape}

Just as significant information about the viewer's space can be derived from the construction of the sculpted figures, so too can the acoustic space of the cathedral be better apprehended from the model when relevant information about construction materials is known. Since churches are typically constructed out of materials with very low absorption coefficients-that is, surfaces that reflect far more sound than they absorb-observers tend to hear multiple reflections of a sound as it travels from its source to the ears of a listener. The timing and location of these reflections augment the listener's sense of a sound's quality and location. These parameters have been most exhaustively investigated in Jürgen Meyer's book Kirchenakustik; the paths of transmission that most commonly affect a listener's experience of sound in churches are shown in figure 6. The first sound to reach the listener, Dir, arrives directly from the sound source. Shortly after the direct sound arrives, reflected sound from surfaces nearest the speaker reaches the listener (the path marked $A$ in figure 6 ). This is followed by reflections that bounce off the lateral surfaces on either side of the listener (path $W$ ), the ceiling and wallceiling juncture (paths $D$ and $W^{\prime}$, respectively), and rear walls facing the listener (path $R$ ). Finally, longer paths of sound that has reflected off multiple surfaces reach the listener (path $\left.D^{\prime}\right) .1$ 


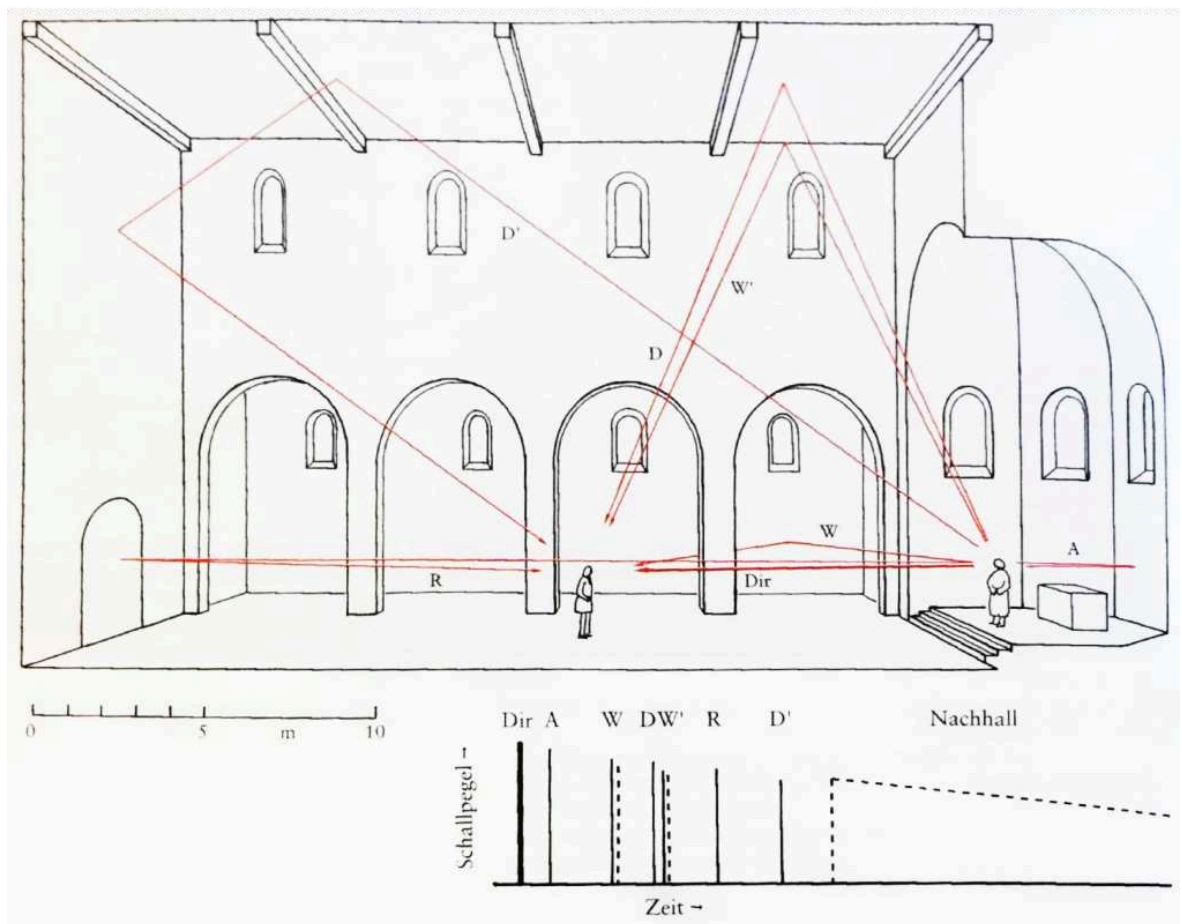

\section{Figure 6.}

Diagram depicting typical patterns of sound transmission in a church, from Jürgen Meyer, Kirchenakustik (Frankfurt: Verlag Erwin Bochinsky, 2003), pp. 43-45.

Recent advances in acoustic computation allow for the simulation of the total number of paths through which a sound is relayed from its source to a given destination. The most advanced program, Odeon Auditorium, allows users to simulate the full range of ISO parameters that gauge an architectural configuration's suitability for musical performance. Using plans and elevations derived from laser scanning, a model of the cathedral was created in Odeon; acoustic absorption coefficients for each material used in the cathedral were assigned to the appropriate surfaces. Six sound sources were placed in the models of the choir stalls and assigned parameters consistent with human singers. The transmission of one singer's voice throughout the cathedral is shown in figure 7 . In the first thirty milliseconds, sound is transmitted throughout the choir; a great deal of it reverberates back and forth between the wooden choir screens. Sound is subsequently transmitted into the transepts (and reflected back into the crossing) and the nave, in which it is reflected off the columns and rear wall. 


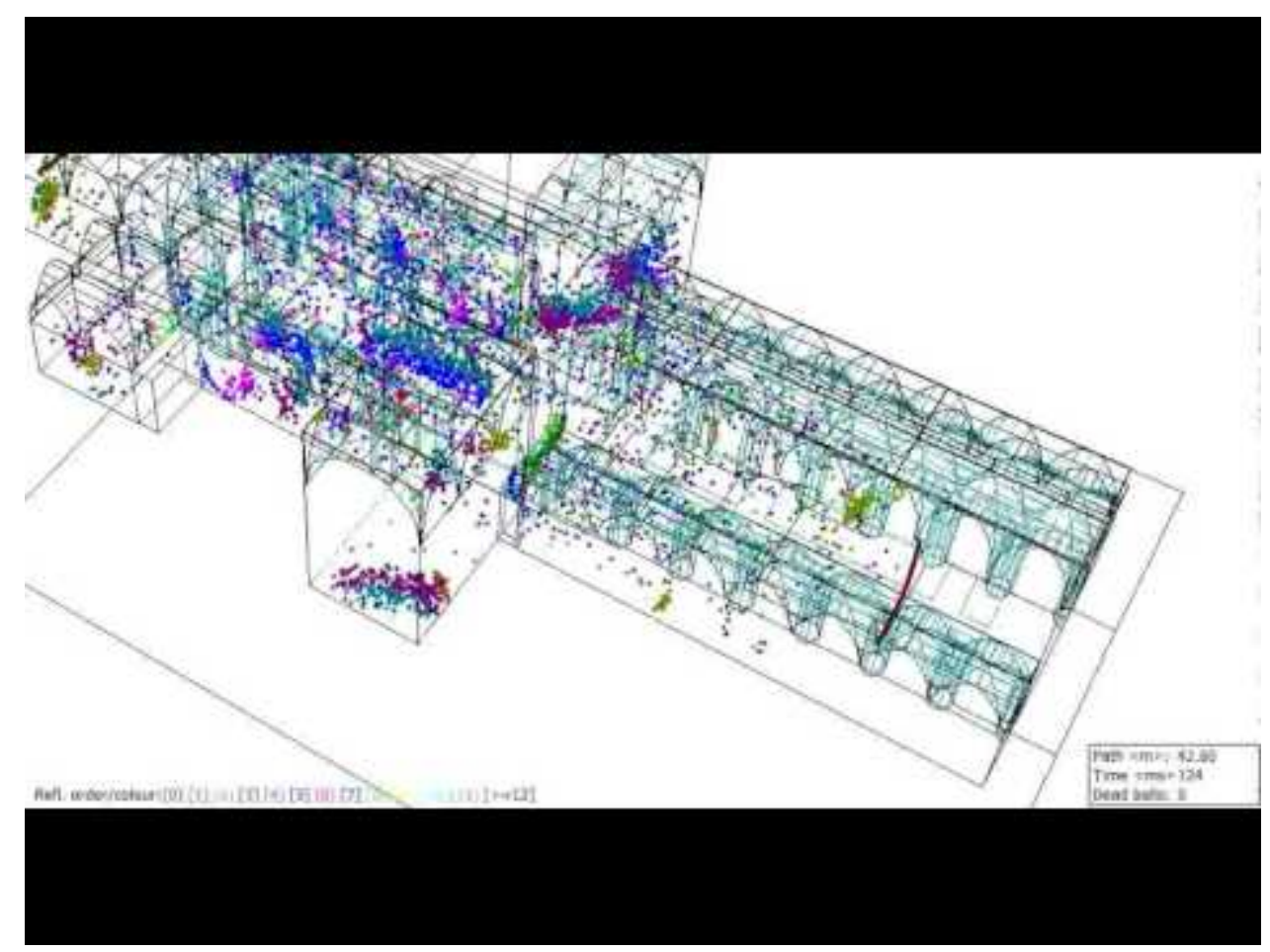

Watch Video

\section{Figure 7.}

Odeon Sound Visualization, Hereford Cathedral, (of human singers situated in the choir). Digital image courtesy of Rendering produced by Justin Underhill

Further analysis reveals a striking correspondence between the visual spaces demarcated by the screen and the soundscape of the cathedral. Since an exhaustive catalogue of the cathedral's acoustic ecology is beyond the scope of this study, I will restrict my discussion to parameters that impacted the visual reception of the screen. As is evident in figures 8 through 10 , one of the most noticeable features of the soundscape for observers who approached the choir would have been the increased acoustic clarity (C80) of sound, objectively measured as the ratio of early to late energy; higher levels of clarity allow a listener to hear distinct notes and sound events without them bleeding into one another. Moreover, the proportion of sound reflected off nearby lateral surfaces relative to overall sound would have also increased. This parameter, commonly referred to as LF80, is shown in figure 11 . In the blue and green segments, relatively little lateral sound is reflected; however, in the yellow and red areas, these levels approach those seen in concert halls. At these levels, the listener experiences a phenomenon known as source broadening, whereby the acoustic space occupied by a sound source seems to grow wider. And indeed, the screen itself seems to anticipate this effect in the bookend placement of the angelic musicians; on each side of the screen, they seem to nearly spill onto the wall of either transept. The screen thereby functioned both as a visual and an acoustic 
frame for the choir and high altar; by virtue of their orientation and placement, the musical figures in the sculptural programme visualize the spatial properties of sounds originating behind the screen in the choir.

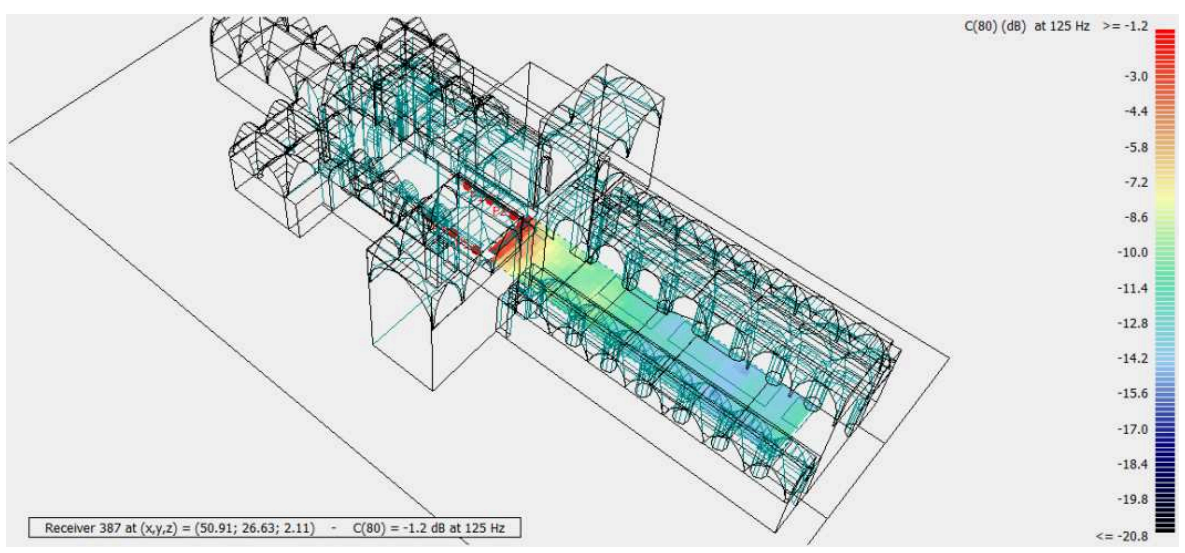

\section{Figure 8.}

Odeon grid map showing distribution of C80 in nave and crossing of Hereford Cathedral, (for human singers situated in the choir). Digital image courtesy of Justin Underhill

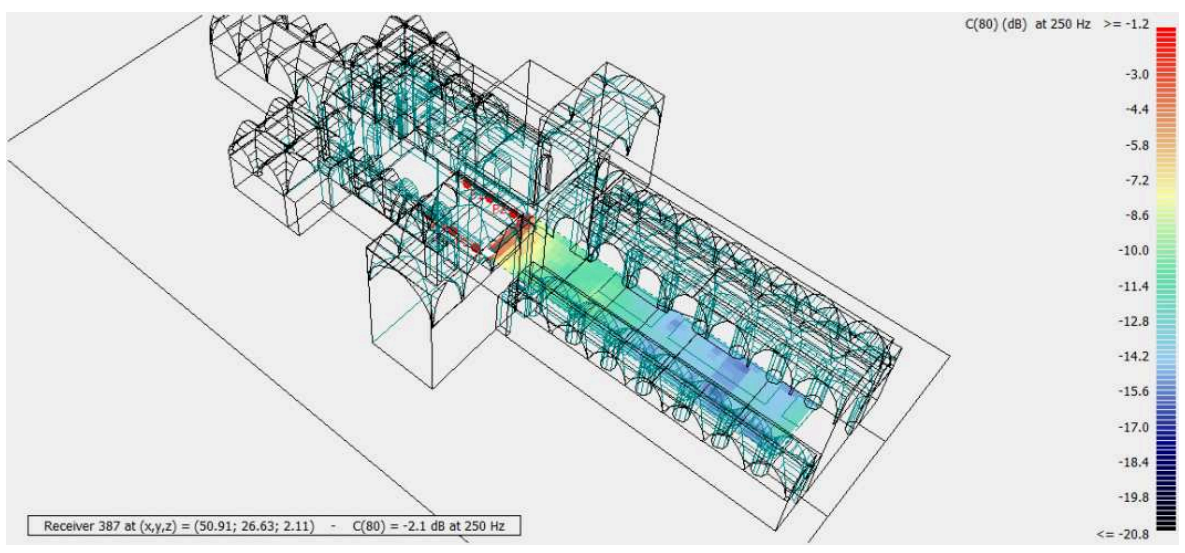

Figure 9.

Odeon grid map showing distribution of $\mathrm{C} 80$ in nave and crossing of Hereford Cathedral, (for human singers situated in the choir). Digital image courtesy of Justin Underhill 


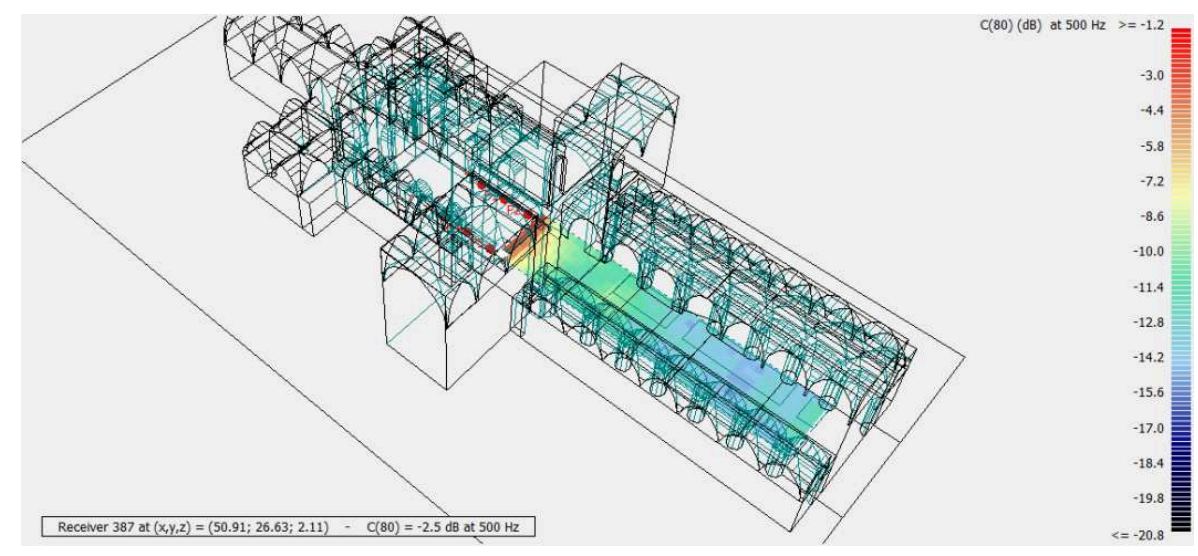

Figure 10.

Odeon grid map showing distribution of C80 in nave and crossing of Hereford Cathedral, (for human singers situated in the choir). Digital image courtesy of Justin Underhill

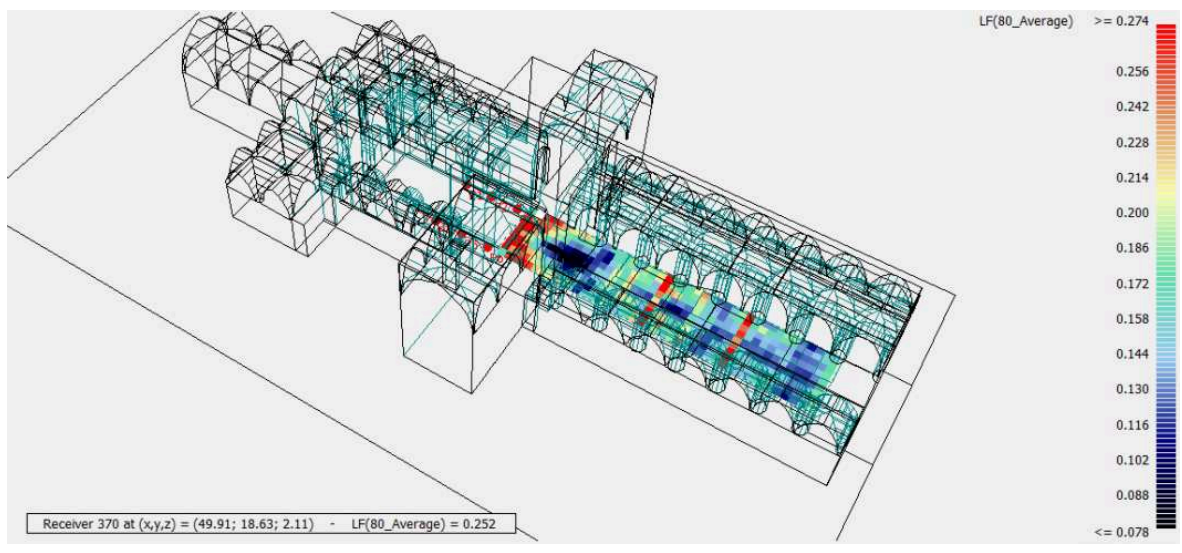

\section{Figure 11.}

Odeon grid map showing LF80 in nave and crossing of Hereford Cathedral, (for human singers situated in the choir). Digital image courtesy of Justin Underhill

The liturgical reforms of the nineteenth century precipitated not only an increase in celebrations of Holy Communion, but also a renewed focus on Anglican ritual space, which was itself in the process of architectural and decorative redefinition. Little surprise, then, that a screen as ornate as the one that once stood at Hereford Cathedral delicately paced the process of devotion for those who approached it. For celebrants of Holy Communion who met Christ's gaze as they approached the high altar, the sculptural ensemble would seem to pictorialize the sound reverberating around them, an acoustic correlate of the sense of presence that the screen so beautifully frames.

\section{Footnotes}

1 This model is described in Jürgen Meyer, Kirchenakustik (Frankfurt: Verlag Erwin Bochinsky, 2003), 43-45. 


\section{Licensing}

The Publishers of British Art Studies are committed to supporting scholarship on British art and architecture of all periods. This publication is made available free of charge at https://www.britishartstudies.ac.uk. We ask users to identify the use of materials made available through this website and to provide an appropriate credit to the to the author and the publication, so that others may find and use our resources.

Except where otherwise noted, this work is licensed under a Creative Commons Attribution-NonCommercial 2.0 UK: England \& Wales Licence (CC BY-NC 2.0 UK). To view a copy of this license, visit https://creativecommons.org/licenses/by-nc/2.0/uk/ or send a letter to Creative Commons, PO Box 1866, Mountain View, CA 94042, USA.

The Publishers fully support the protection of intellectual property and are committed to complying with, and strictly adhering to, all applicable copyright law. In many cases, copyright or other proprietary rights may be held by individuals or entities other than, or in addition to, the Publishers. If a work or a photographic image is still protected by copyright, you must cite the relevant copyright information when using the image and comply with all other terms or restrictions that may be applicable to that material.

In some cases, exceptions to copyright that permit limited use of protected works without the permission of the copyright owner may have be applied. We are confident that we have carried out due diligence in our use of copyrighted material as required, but we apologise for any inadvertent infringement of rights.

Digital copies of resources are made accessible for research for one of the following reasons:

- they are in the public domain;

- the rights are owned by the Publishers;

- we make them accessible under an exception or limitation to UK copyright law, as outlined in the Copyright, Designs and Patents Act 1988 (as amended);

- we have permission to make them accessible;

- or, there are no known restrictions on use.

If you believe that we have made a mistake and wish for your material to be removed from our site, please contact us at copyright@paul-mellon-centre.ac.uk.

Please include the following information with your request:

- Name and contact information, including email address and phone number.

- Identification of the resource for consideration of removal. Providing URLs in your communication will help us locate content quickly.

- The reason for the request.

The Publishers respond promptly, normally within 21 business days. We may remove the resource from our site while we assess the validity of the request. Upon completion of the assessment, we will take appropriate action and communicate that action to you. 